\title{
Which amount of fluid do we need to evaluate preload dependency?
}

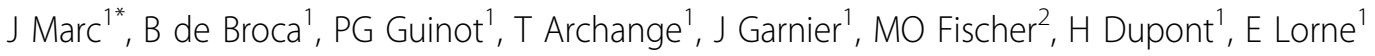 \\ From ESICM LIVES 2015 \\ Berlin, Germany. 3-7 October 2015
}

\section{Intr}

Cardiac output optimisation is based on stroke volume (SV) variations with fixed volume expansion (VE) or use of dynamic preload indices. The amounts of volume and thresholds used for SV increase vary between studies.

\section{Objectives}

The objective of this study was to evaluate the ability of the stroke volume (SV) variation with $250 \mathrm{ml}(\Delta 250 \mathrm{SV})$ of volume expansion (VE) to predict further SV increase with VE. We also studied the ability of respiratory SV variation $(\Delta$ respSV) to discriminate fluid responisvenness according to the amount of VE (250 then $500 \mathrm{ml})$. Fluid expansion consisted on infusion of $500 \mathrm{ml}$ of Ringer lactate fractioned by step of $250 \mathrm{ml}$ over $10 \mathrm{~min}$.

\section{Methods}

After IRB approval, 48 patients ventilated with a tidal volume of $7 \mathrm{ml} / \mathrm{kg}$ and monitored by an oesophageal Doppler were included. Hemodynamic (heart rate, blood pressure) and ODM (peak velocity (PV), stroke volume (SV), corrected flow time (FTc), cardiac output (CO), $\Delta$ respSV) data were collected before VE, after $250 \mathrm{ml}$ and $500 \mathrm{ml}$. Responders (R) were defined by an increase $\geq 10 \%$ of SV after VE. We defined three groups : Non-responders (NR), Responders at 250 and $500 \mathrm{ml}$ of VE (R) and Non-responders at $250 \mathrm{ml}$ but Responders at $500 \mathrm{ml}$ of VE (NR250). Data were compared by ANOVA with post-hoc analysis and Mann Whitney test. A ROC curve was constructed for $\Delta$ respSV250, $\Delta$ respSV500 and $\Delta 250 \mathrm{SV}$.

\section{Results}

Of the 48 patients, 18 (38\%) were classified as NR, 17 (35\%) NR250 and 13 (27\%) R. In the overall population, 30 patients increased SV over $10 \%$ after $500 \mathrm{ml}$ of VE.
In the NR250 group the average $\Delta 250 \mathrm{SV}$ was $8 \%\left(\mathrm{IC}_{95}\right.$ : 6-10) and 11 (23\%) patients had a $\Delta 250 \mathrm{SV}$ less than $10 \%$ whereas they were responders for $500 \mathrm{ml}$ of VE. The $\triangle 250$ SV AUC was 0,9 (IC $95: 0,79-0,97), \mathrm{p}<0,001$, with an optimal threshold at $7 \%$. The $\triangle$ respSV AUC differed with the amount of VE used $\left(0,76\left(\mathrm{IC}_{95}: 0,62-0,88\right)\right.$ for $250 \mathrm{ml}$ and $0,87\left(\mathrm{IC}_{95}: 0,74-0,95\right)$ for $\left.500 \mathrm{ml}, \mathrm{p}<0,05\right)$.

\section{Conclusions}

In this study, VE with $250 \mathrm{ml}$ of crystalloid solution hid $50 \%$ of the responders for $500 \mathrm{ml}$. For a VE titration, a $\Delta 250 \mathrm{SV}$ threshold at $10 \%$ could miss an important number of preload dependant patients. Predictability of dynamic preload indices vary according to the amount of VE. It could be related to crystalloid expansion power effect.

\section{Authors' details}

${ }^{1}$ Univ. Hospital Amiens, Amiens, France. ${ }^{2} \mathrm{CHU}$ Côte de Nacre, Caen, France.

Published: 1 October 2015

doi:10.1186/2197-425X-3-S1-A238

Cite this article as: Marc et al:: Which amount of fluid do we need to evaluate preload dependency? Intensive Care Medicine Experimental 2015 3(Suppl 1):A238. 